\title{
Research on Brand Positioning and E-business Marketing Strategy of Sports Goods based on Network Questionnaire
}

\author{
Wusong Tang \\ Physical Education College, Shihezi University, Shihezi 832003, Xinjiang, China \\ tangwusong123@163.com
}

\begin{abstract}
The development of the Internet has brought great opportunities for the sales of sports goods, so that enterprises should make the right online marketing strategy. This paper takes the consumer perception as the research content, study on the influence of different brand positioning factors on consumers by using empirical analysis. The results show that the factors affecting of brand can be divided into four categories as quality, product, service and social attributes. Among them, the quality is the most significant and the cumulative contribution rate is 79.532. Based on factor analysis method, the author identifies the main advantages and disadvantages of these brands, thus companies can effectively formulate the corresponding brand marketing strategy.
\end{abstract}

Keywords: E-business, sports goods, network questionnaire, marketing strategy

\section{Introduction}

With the rapid development of Chinese economy, domestic sporting goods production continues to improve, in the eighties of the last century, sports goods enterprises in our country does not produce belongs to own brand products, the vast majority of OEM processing production. With all aspects of the maturity of the conditions, Anta began to create their own brand, then to sell sports shoes mainly, the higher visibility of the Lining brand also appeared[1]. Because at that time, Chinese consumers are more sensitive, the demand for sports brand is very easy to be satisfied; the competition among enterprises is relatively small, resulting in a single sport brand variety. In the early 1990s, Asian financial crisis, the economic situation remains in the doldrums, resulting in substantial reduction of export orders, inventory backlog is more and more, many sports brand enterprises began to realize only by establishing a proprietary sales channels to change this situation. When Li Ning, Anta, 361 degree brand visibility is more and more high and in the nationwide opened several stores, have their own marketing channels, more perfect after-sales service system, brand benefit is gradually attaches importance to the enterprises.

The end of last century, a large number of internationally renowned brands into the Chinese market, no doubt to the domestic sporting goods market have brought a threat. Most of the domestic consumers for curious psychology and the quality standard of living improve, attention gradually shifted to the Adidas, Nike and other well-known brands abroad[2]. At the same time, domestic middle and low brand also appears in succession, economic benefits is its advantage, so more and more brand information filled in the minds of the consumers, leading to consumers to buy the product less emotional and impulsive but more rational, demand is difficult to be satisfied. Brand Company can only meet the needs of different consumer groups to make the product better to sell out, so the seller's market is gradually transferred to the buyer's market[3]. But so far the attention of the international brand Nike is still the first, followed by Adidas, the domestic brand of concern is relatively low. Face this kind of situation, the small local brands to find belongs to own consumer groups in order to achieve better development; domestic large 
and medium-sized brands such as Li Ning, Anta, how to play to our strengths and avoid disadvantage, in the gap in the double attack, come to the fore. These problems reveal the importance of the brand positioning strategy. Therefore, the sports goods manufacturers only make accurate brand positioning, in order to create a good brand image, so as to develop effective marketing strategies to maintain and expand their market share. As the brand positioning is directly affect the sales target, determine the success or failure of the business.

So far, Chinese sporting goods market is still in the initial stage, most sports brand is still constantly exploring in advance, social progress and economic growth promotes the improvement of people's living standards, especially one, and second tier cities consumer needs to rise gradually, started from the mid-market transition to high-end market. In addition, part of the more affluent rural residents by a began on low-grade products love is gradually changing, the psychological demand is also difficult to meet, so domestic sporting goods enterprises in the future development prospect is very wide[4]. Due to the interest of outdoor sports and tourism projects is more and more strong, every year more and more people to participate in outdoor sports, so that the products in the Chinese market sales will continue to expand, there is great hope to become the future of domestic sales of the largest scale and growth the fastest sports activities. In our country to increase sports goods export at the same time, must also committed to export production technology, equipment research and development and joint venture factories, provided by the raw materials and semi-finished products gradually transformed to brand registered in foreign countries, such as, improve product processing depth and added value. In the impact of the international market, the choice of accurate market positioning is the key. In towards the international market, cannot be all smooth sailing will downs, because the brand in the world with a long history, market position has been quite stable, domestic brands is very difficult to have shelter, should be proactive the lack of international brand marketing countries and regions, some territory has not been involved in the development, such as actively engaged in border trade.

This paper from the consumer point of view, the sporting goods brand positioning were exploring and studying, the meaning is reflected in the following two points: through empirical research can make the enterprise directly found consumers in the purchase of the product value of factors, so in a timely manner to determine the brand positioning to; the second is through the performance index difference between comparison of five wellknown brands as Adidas, Nike, Li Ning, Anta, Hongxing erke, companies can see their own advantages and disadvantages, for enterprises to formulate correct marketing strategy provides the basis[5]. With the progress of society and the improvement of economic level, facing the well-known foreign brands of development more and more rampant, domestic low awareness of the brand is becoming more and more mature, highlights the growing importance of brand positioning, but most enterprises haven't mastered the essence, so the brand positioning poor specificity of true objective data based on, by comparing with representative sporting goods brand, combined with the psychological characteristics of the consumer, for enterprises to formulate the precise positioning of the brand and the right marketing strategy to provide a reference. The consumer perception perspective, for the sporting goods brand, through field research obtain different brand positioning elements on the consumer's influence and perceived where, in order to make clear the brand positioning of the main strengths and weaknesses; and the above investigation data, through analysis and statistical analysis methods for the final data analysis, for the relevant decision-making industry brand positioning reference, formulate corresponding brand marketing strategies. In this paper, the theoretical analysis and empirical research methods are combined to explain the brand positioning of sports goods. Main idea: in theoretical analysis, emphasizing to study the integration of the consumers perception theory, theory of target market strategy, brand positioning theory and brand image theory, and emphasizes the importance of under the premise of the enterprise market segmentation, brand positioning is based on consumer perception of the brand image of the core, sporting goods brand positioning ideas clear. In the empirical research, 
emphasizing the investigation questionnaire based on, a large number of consumers for different brand positioning sensor data collection and processing, and thus as a statistical analysis of the data source, thus ensuring the this paper to represent the brand as an example, empirical research to verify the hypothesis, thus revealing the regularity conclusion, and proposes the Countermeasures for the industry. This study first put forward the theoretical foundation of the research: including consumer perception, STP strategy, brand positioning, brand image related theoretical research; then analysis the status and problems of the sporting goods brand positioning, establish inspection sporting goods industry brand positioning of various important factors, and puts forward the research hypothesis; followed by empirical research, relying on questionnaire survey to get consumers to various domestic and international sporting goods brand image of cognitive data, so as to clarify the situation comparison of current sports enterprise brand positioning, and to test the hypothesis; finally through the empirical results, put forward opinions and suggestions for domestic sports brand marketing strategy.

\section{Literature Review}

\subsection{Consumer Perception Theory}

Brand must be positioning them to meet consumer demand for the position. However, consumer psychology is the theoretical basis of brand positioning, which consumer perception is one of the important concepts in consumer psychology, is a product and a brand to compete in the beginning. The effectiveness of consumer perception often determines the effectiveness of the product and brand. Consumer perception is the inducing agent to produce and induce consumer behavior. It plays a guiding role in consumer choice, understanding, organization and consumption function, and it plays a leading and special effect[6-7]. Perception of consumer perception is an important psychological concept; it is through the sense organs to make the objective things directly reflected in the human brain. Perception is the process of a system, and it is the process that individual has the choice of feeling, observation, understanding and memory. The definition of perception should reflect the continuity of mental process. In psychology, perception is the process of selecting, organizing and explaining the meaningful and related images. Consumer perception is the consumers according to their product demand situation and purpose of use and comprehensive analysis of various regular or non-regular accesses to relevant information, to a service or a product to make the abstract subjective evaluation. Therefore, consumer perception is consumers' subjective feeling, perceived value, is a repeat of the complex psychological process.

Image sensing theory that consumers to the brand overall perception on behalf of the brand image, consumers on the brand of reasoning and judgment basis and dependent external stimuli or imagination and the formation of consumer perception is individual experience, selecting, organizing and interpreting information, and make the information and a determination of the cognitive structure of analogues is associated, so as to form the image perception[8]. Under the condition of incomplete information, the visibility of the product acts as a clue to the potential quality information, and the consumer's perception of the quality directly influence the purchase intention and behavior of the consumers. In the study of consumer perceived quality, it is divided into four aspects: quality reliability, quality effect, finishing quality and safety. Consumers rely on price, quality and value perception to evaluate the product, is a kind of subjective judgment, rather than based on the property of the product and makes the objective evaluation. At present, most of the researches on consumer perception theory focus on the research of customer perceived quality and customer perceived value. The consumer perceived value is defined as the value that is created by the supplier to the supplier for the value of the given value in a specific state of use, when the consumer is weighed against a given value. Consumer perception should include value perception, quality perception and brand association. By 
studying the theory of consumer perception, the concept and classification of it are understood. This knowledge provides help to the design of the questionnaire, and the theory of consumer perception will also help to understand the specific decision-making process. But it should also be seen that there is no uniform standard on consumer perception, in the future research, it should be combined with the nature of the consumer perception of the industry.

\subsection{Market Segmentation Theory}

Academic circles at home and abroad to use market segmentation method are mainly the following three: first called pre segmentation method, namely before the study has been selected segmentation criteria, the theoretical basis is consumer behavior model, to get the final segmentation groups depending on the results of the researchers on the consumer behavior of qualitative analysis[9]. The second kind is the ex post subdivision, the research of this kind of subdivision has not been confirmed by the dependent variable, that is, the classification of the standard categories and the number of the final segments. The third method is factor analysis, which is using factor analysis to reduce the dimension of variables, so as to get the result of cluster analysis by cluster analysis. Its theoretical basis is the statistical analysis of the survey of consumer results using statistical methods and derived consumers clustering characteristics. Not all market segments can have a certain appeal to the enterprise, even if a certain market segments has appropriate size and growth rate, also have structural attractiveness, enterprises still need to consider the objectives and resources is matched with the market, and each enterprise existing human, financial, material and information resources is limited, cannot meet the needs of the market, enterprises only according to the existing resources and their own competitive advantage to choose suitable for their target market, don't in the development process of many detours. No difference marketing strategy: refers to the enterprise does not consider the difference of market segments, to provide a marketing mix for the entire market.

The focus of this marketing strategy is the need for consumers to be on the common rather than differences. It is the design of the marketing plan to attract the most buyers, mass distribution and mass advertising is the most basic marketing tool, the purpose of advertising is to create a good image in the minds of consumers. This strategy can greatly reduce the production cost, but it is difficult to development mission to all consumers are satisfied with the products and services, or even to meet the needs of the majority of consumers are difficult to achieve; marketing difference: refers to enterprises to choose several segments of the market as the target market, and separately for each target market marketing design scheme of a kind of strategy[10]. Differential marketing strategies generally produce more total sales than non-differential marketing strategies. At the same time it is also relatively high cost. Focused marketing strategy: it is especially attractive to companies with limited resources. The use of such a strategy is not to occupy a small share of the big market, but to pursue one or several small market share. Through the centralized marketing strategy, enterprises in their service market segments formed a strong market position, because they are more aware of the needs of these market segments. If the market segments selected properly, companies can get a high rate of return on investment. At the same time, it also implies a higher risk. The three strategies have their advantages and disadvantages, and enterprises need to take into account many factors when choosing a market coverage strategy. One factor is the company's resources. When the enterprise resources are limited, the most appropriate strategy is to focus on marketing strategy. Another factor is the degree of homogeneity of the product. For homogeneous products, the more appropriate strategy is no difference strategy. In addition, we must also consider the product life cycle stage, the market homogeneity, competitors strategy and other factors, only grasp these factors, in order to choose a suitable target market. 


\subsection{STP Strategic Theory}

Through the review and collation of the relevant literature of STP strategy theory, we first understand the basis and model of market segmentation, and understand the method of market segmentation. STP strategic theory, market segmentation, target market selection and market positioning as the core of the framework of the system. The back for sporting goods market segmentation can provide certain basis; secondly also learned the three kinds of strategies of target market selection, to determine the target groups for the sporting goods industry [11]. Finally, the market positioning and several main theoretical have more in-depth understanding, because the brand positioning is the core of market positioning, only to understand the theory of market positioning, in order to behind the sporting goods brand positioning provide theoretical basis. However, it should also be noted, although the market segmentation theory has developed relatively mature, but did not according to the standard of segmentation of a particular industry, due to the different characteristics of different industries; the future can be in a particular field to study the target market positioning strategy. Under the condition of modern market, consumer demand is diverse, and there are a large number of people, is widely distributed, any enterprise could not to their own limited resources to meet the needs of the market all consumers of various requirements. Through market segmentation, it is the basic premise of brand positioning to provide products or services with their own advantages to the specific consumer groups in the market.

After the market segmentation, the enterprises choose the target market to carry on market positioning, market positioning is the premise of brand positioning, brand positioning is the specific form of market positioning, and the two complement each other. Through the study of domestic and foreign brand positioning theory, connotation of brand positioning and research methods have certain understanding, brand positioning is to let the brand occupy the minds of consumers advantageous position, with the aid of the effective means of communication, establish a good brand image transfer to the minds of consumers[12]. But we should also see that brand positioning factors in different industries should have great differences, but previous studies for the sporting goods industry is relatively small, this deficiency can be made up in this study. Brand positioning is clear, and then the brand personality can be more clearly reflected. The brand emotional appeal can be reflected through the brand personality, and ultimately to establish a brand image. The brand image is the consumer's cognition, which directly determines whether the brand positioning is accurate or not. Therefore, it is necessary to understand the relevant theory of brand image.

\subsection{Concept of Brand Image}

Brand image evaluation will help enterprises to correctly evaluate the effectiveness of the previous brand marketing efforts, to further create an ideal brand image to provide decision-making basis. Since the concept of brand image and connotation of the brand image especially evaluation research in the very long time has not been much progress, until the late 1980s around study and review on the theory of brand image through the analysis and research of brand image theory, to understand the concept of brand image and related evaluation model. Based on brand positioning is the basis of the establishment of the brand personality and brand image, and shaping the brand personality and brand image to detect brand positioning accuracy, this paper selects brand of sports activities to provide reference, providing references for the design of the questionnaire, and sports related businesses to develop marketing strategy to provide advice. But needle for different industry brand image evaluation model should be differentiated, the lack of relevant theoretical study, expect to explore suitable for various industries of brand image evaluation model to make up for the deficiency. 


\section{Empirical Study}

\subsection{Research Design}

According to the current domestic sports brand positioning problems, can the empirical research approach consists of four steps: the first step research hypothesis of this paper, the positioning strategy of sports goods enterprises will have different influence on consumers' perception; determine the index factors of the second step, design questionnaire preliminary test and formal test, test the group is divided into designated school students and representative social young people, testing methods including field testing and network testing; the third step to collect the questionnaire effectively, which makes descriptive and factor analysis by SPSS software and the data of questionnaire; the fourth step conclusions verify the hypothesis, and the analysis conclusion for the domestic sports activities to enhance the brand image to find the suitable marketing strategy.

\subsection{Indicators and Collect Data}

So far, China sports brand more and more, but the difference is getting smaller, thus leading to consumers in the purchase of the product into the location factors are many, become more rational. Therefore, this paper puts forward the research hypothesis: positioning strategy of different enterprises will on consumer perception of impact, thereby affecting consumer purchasing decisions. Combined with the characteristics of the sporting goods industry and the positioning problem summarize and extract information of internal secondary data and in-depth interviews with consumers. In this paper, a preliminary summary of the seven first level indicators, including product, price, service, brand image, information channel, locations and social attributes. It is based on these factors, different companies have developed different positioning strategies, resulting in the perception of consumers vary. In determining the indicator variables, the main use of the three ways: one is to read a large number of domestic and foreign sports activities on the literature in the useful information recorded.; the second is through market research, and professionals of in-depth interviews to collect information; the third is within the network media and newspaper media, timely attention at home and abroad especially well-known sports brand news and trends and the depth of thinking, to establish the index system based on two aspects: one is based on the maturity of the brand positioning theory and in the research were repeatedly mentioned; the second is the alignment index sequence with the habit of thinking of consumer, has a certain logic. Because of the secondary indicators of the project and the degree of influence of the vast majority of consumers are not necessarily the same, some indicators may effect on the part of consumers of another part of consumers influence is very small, to this phenomenon, for empirical research is more accurate and feasible, first preliminary test, is pre testing, to determine the final investigation index. The effective data through SPSS descriptive statistics analysis method of index of mean and variance analysis, in order to ensure finally selects the factor validity and concentration, select the following as a formal test indicator variables, the results are shown in table 1.

This paper is empirical research on brand positioning for the sporting goods business for, due to the sporting goods enterprises belonging to its own characteristics, face market consumer groups and other industries is different, only the results is accurate, feasible, valuable to the enterprise develop effective marketing strategy to provide some guidance, so in the investigation of group selection, sex to uniform percentage, age to representative, education should also consider because of today's college students is the main force of the consumer, finally monthly disposable income level is the key factor, it with the people's consumption level is closely related, descriptive statistical analysis of the formal questionnaire. 
Table 1. The Mean Standard Deviation Analysis

\begin{tabular}{|c|c|c|c|c|c|}
\hline index & $\begin{array}{l}\text { mean } \\
\text { value }\end{array}$ & $\begin{array}{l}\text { standard } \\
\text { deviation }\end{array}$ & index & $\begin{array}{l}\text { mean } \\
\text { value }\end{array}$ & $\begin{array}{l}\text { standard } \\
\text { deviation }\end{array}$ \\
\hline $\begin{array}{c}\text { Product } \\
\text { uniqueness }\end{array}$ & 3.79 & 0.885 & Easy washing & 4.20 & 1.066 \\
\hline Fashion & 3.62 & 0.822 & Value for money & 4.05 & 0.766 \\
\hline Design details & 4.00 & 0.842 & $\begin{array}{c}\text { Sales staff } \\
\text { attitude }\end{array}$ & 4.33 & 0.862 \\
\hline Product mix & 3.82 & 0.843 & after-sale service & 4.51 & 0.825 \\
\hline Color selectivity & 4.26 & 0.931 & Brand awareness & 4.12 & 0.917 \\
\hline Full size & 3.85 & 0.818 & Word of mouth & 3.78 & 0.816 \\
\hline $\begin{array}{l}\text { Measurement } \\
\text { specification }\end{array}$ & 4.07 & 0.886 & $\begin{array}{c}\text { Cultural } \\
\text { characteristics }\end{array}$ & 3.53 & 0.982 \\
\hline Fabric texture & 4.02 & 0.859 & Brand value & 3.75 & 0.880 \\
\hline fine workmanship & 4.40 & 0.869 & $\begin{array}{l}\text { Convenient } \\
\text { traffic }\end{array}$ & 4.03 & 0.898 \\
\hline Comfortable & 4.27 & 0.887 & $\begin{array}{l}\text { Self image } \\
\text { satisfaction }\end{array}$ & 4.21 & 0.843 \\
\hline wear-resisting & 3.37 & 0.919 & Product style & 4.34 & 0.877 \\
\hline Protection level & 4.65 & 0.964 & $\begin{array}{c}\text { Sense of } \\
\text { belonging }\end{array}$ & 3.66 & 0.884 \\
\hline
\end{tabular}

\subsection{Factor Analysis}

In this paper, the difference between the sports brand, so choose at home and abroad is representative of the sports brand Adidas, Nike, Li Ning, Anta, Hongxing erke as the object of the factor analysis. Factor analysis is a method that can evaluate the abstract factor through the evaluation of the latent variables in the variables. The purpose is to reduce the dimension. The basic principle is to replace the most information of the original variable with a few independent variables. Steps can be divided into the following four steps: one is the correlation matrix is computed, test the reliability and validity, the correlation between the variables examined; the second is using principal component analysis method is used to extract the initial factor; the third is the initial factor rotation; the fourth is through the public factor for each factor, a reasonable explanation. In this paper, we test the reliability and validity of the data variables corresponding to the five brands by using SPSS 19 software, as shown in table 2.

Table 2. KMO and Bartlett's Test

\begin{tabular}{|c|c|}
\hline Kaiser-Meyer-Olkin Measure of Sampling Adequacy. & .886 \\
\hline Approx. Chi-Square & 1660.50 \\
\hline df & 365 \\
\hline Sig. & .000 \\
\hline
\end{tabular}

\subsection{Empirical Results}

Different brands of principal component factor variance contribution rate as shown in the following table, the brand from high to low followed by quality, products, services and social attribute, and the platoon is in the first principal component factor and the remaining three gap is very obvious, cumulative contribution rate is higher that the four factors is representative, can be used to interpret the information of most of the indicators.

Table 3. The First Four Factors Variance Explained of Adidas 


\begin{tabular}{|c|c|c|c|}
\hline \multirow{2}{*}{$\begin{array}{c}\text { Principal } \\
\text { component factor }\end{array}$} & \multicolumn{3}{|c|}{ square sum of the load } \\
\cline { 2 - 4 } & characteristic value & $\begin{array}{c}\text { Variance } \\
\text { contribution rate }\end{array}$ & $\begin{array}{c}\text { Cumulative } \\
\text { contribution rate }\end{array}$ \\
\hline 1 & 10.241 & 49.863 & 49.863 \\
\hline 2 & 2.140 & 12.785 & 61.647 \\
\hline 3 & 1.703 & 10.653 & 72.210 \\
\hline 4 & 1.422 & 7.333 & 79.532 \\
\hline
\end{tabular}

Table 4. Factor Matrix after Rotation of Adidas

\begin{tabular}{|c|c|c|c|c|c|}
\hline \multirow{4}{*}{ factor } & Index & \multicolumn{4}{|c|}{ Components } \\
\hline \multirow{4}{*}{ quality } & Fabric texture & 0.721 & 2 & 3 & 4 \\
\hline & Wear resistance & 0.715 & & & \\
\cline { 2 - 6 } & color & 0.625 & & & \\
\cline { 2 - 6 } & Easy to wash & 0.781 & & & \\
\cline { 2 - 6 } & Fashion & & 0.677 & & \\
\cline { 2 - 6 } Product & Design details & & 0.572 & & \\
\cline { 2 - 6 } & Complete number & & 0.562 & & \\
\cline { 2 - 6 } & Color selection & & 0.643 & & \\
\hline \multirow{4}{*}{ service } & Value for money & & & 0.683 & \\
\cline { 2 - 6 } & Sales staff attitude & & & 0.772 & \\
\cline { 2 - 6 } & after-sale service & & & 0.720 & \\
\hline \multirow{2}{*}{ Social attributes } & Sense of belonging & & & & 0.769 \\
\hline & Style and personality & & & & 0.671 \\
\hline
\end{tabular}

Adidas and Nike are two well-known foreign brands in the world of sports goods industry leader, in the brand's performance is almost the same, the principal component factor plays a leading role in the quality of products and services, and social attributes, the quality is the most significant, this is the two have been focused on innovative product development and on the result, this also with their market positioning in the high-end brand is the same, in addition to the pursuit of product quality excellence with almost every sports goods consumers are thought to have felt a sense of belonging to Adidas or Nike will, self-confidence can be increased, the psychological needs can be met, the social attribute and they have been positioning are inseparable, visible, accurate positioning of the two brands of domestic sports enterprises worth learning, it can serve as a benchmark for enterprises.

Through the above analysis of the domestic sports brand positioning of different grades of factors, with the continuous improvement of economic level, people's life is more and more wealthy circumstances, consumers face the diversification and individuation of the psychological needs of brand strategy for enterprises is indispensable, so the domestic sports enterprises have accurate positioning and according to the trend of the times adjust and change is crucial, the enterprise can enhance the social attribute of products, guarantee the quality of the product, rebuild the brand image, expand publicity channels, improve the overall quality of service, so as to strengthen the brand positioning strategy, to provide intellectual support for enterprise's marketing strategy, only in this way, can we get the brand advantage, brand marketing to be successful thus, to expand their market share, maintain market stability, improve profitability, and ensure the good prospects for the development of enterprises, so that enterprises in an invincible position. 
Table 5. The First Four Factors Variance Explained of Nike

\begin{tabular}{|c|c|c|c|}
\hline \multirow{2}{*}{$\begin{array}{c}\text { Principal } \\
\text { component factor }\end{array}$} & \multicolumn{3}{|c|}{ square sum of the load } \\
\cline { 2 - 4 } & characteristic value & $\begin{array}{c}\text { Variance } \\
\text { contribution rate }\end{array}$ & $\begin{array}{c}\text { Cumulative } \\
\text { contribution rate }\end{array}$ \\
\hline 1 & 7.553 & 48.663 & 48.663 \\
\hline 2 & 1.995 & 11.240 & 59.803 \\
\hline 3 & 1.705 & 10.316 & 70.119 \\
\hline 4 & 1.458 & 7.402 & 77.522 \\
\hline
\end{tabular}

\section{Conclusions}

With the rapid development of the society, under the guidance of national policies, stimulating economic growth, China sporting goods production also show a rising trend and greatly, but due to the continuous improvement of people's living standards, consumer demand becomes more and more difficult with the foot, accompanied by foreign famous brand a lot squeezed into the Chinese market, domestic sporting goods enterprises by serious challenges, in terms of brand image obvious deficiency, and foreign brands and the gap is very big. Based on chapter empirical analysis results, can be found which in the various elements of the brand positioning and product quality, brand image, social attribute, service quality accounted for the proportion of highest in terms of the quality of products, with Anta, Hongxing erke, two local brands as the representative of the low grade brand significantly worse than foreign brands and domestic high-end brands, in the social attribute and foreign brands also differs very far, almost unable to meet the psychological needs of consumers, the brand image is not dominant, awareness needs to be improved, quality of service also has space for further improvement. Therefore domestic sporting goods enterprises to think and Adidas, Nike and the two benchmarking enterprise competition, walk in the top of the market structure, occupy a certain market share, we must recognize the importance of brand positioning, brand positioning accurately determines the shaping the image of the brand, a good brand image will have a positive impact on the brand marketing strategy, so, following the domestic sporting goods enterprises are classified as three grades to Li Ning as the representative of the high-end brand, Anta on behalf of mid-range brand, erke as representative of the lowgrade brand, respectively for the proposed guidance and advice on marketing strategy.

Domestic brands to compete with foreign brands, and strive for greater market share, how small domestic brand development in the cracks, keep their own competitive advantages, have their own market position and these problems are attributed to problems in the brand development strategy, and brand positioning is the foundation of the brand development strategy, is the problem of many enterprises are facing, this paper starting from the perspective of consumers, for the sporting goods business, using the method of theoretical analysis and empirical research combined with the interpretation of sports brand positioning strategy, thus for the sports goods enterprises to develop brand positioning strategies provide the basis for the correct and effective marketing strategy. Due to the perception of consumers is an important concept of consumer psychology, consumer psychology is the theoretical basis of brand positioning, market positioning is the premise of brand positioning, brand positioning and dependent on the spread of brand image. So this paper on consumer perception theory, STP theory, strategic theory of brand positioning, brand image theory research, which not only provides theoretical support for the research of this paper, but also provide a basis for the design of empirical research in this paper questionnaire, finally provides reasonable suggestions for the marketing strategy formulation; followed by general situation of development of sports goods enterprises, analysis of localization, reveals the existing in the brand positioning in the sporting goods business, and summarizes seven kinds of location factors, including 
product, price, service, brand image, information channel, address and social attribute, this paper's empirical research pave the way; the research supposition, determine the object of investigation, the study sample, variables questionnaire after using descriptive statistical analysis method and Factor analysis method was used to analyze the data, for five with representative sports brands come to the conclusion of the empirical research, in order to verify the research hypothesis, the effect of sporting goods enterprises in different positioning strategies on consumer perception is different; finally is based on the results of empirical research, the domestic sporting goods brands are classified, divided into three levels of high-end, mid-range, low-grade, respectively, for different levels of brand according to the empirical study results, this paper puts forward effective marketing strategy, improve its competitive advantage, subsequently expanded its market share.

\section{Acknowledgements}

This paper is supported by Project of Humanities and Social Sciences Cultivation Fund for young researchers in Shihezi University: "Study of Urban Residents Sports Consumption in Production and Construction corps" ( RWSK14-Y15).

\section{References}

[1] Z. Huang and M. Benyoucef, "From e-commerce to social commerce: A close look at design features", Electronic Commerce Research and Applications, vol. 12, no. 4, (2013), pp. 246-259.

[2] L. Louis and É. Lefebvre, "Exploring B-to-B e-commerce adoption trajectories in manufacturing SMEs",Technovation, vol. 25, no. 12, (2005), pp. 1443-1456.

[3] L. Michel and R. Mohammad, "The effects of social media based brand communities on brandcommunity markers, value creation practices, brand trust and brand loyalty", Computers in Human Behavior, vol. 28, no. 5, (2012), pp. 1755-1767.

[4] D. Rosaci, "Multi-agent technology and ontologies to support personalization in B2C E-Commerce", Electronic Commerce Research and Applications, vol. 13, no. 1, (2014), pp.13-23.

[5] K. Anand, "Context-general and Context-specific Determinants of Online Satisfaction and Loyalty for Commerce and Content Sites", Journal of Interactive Marketing, vol. 24, no. 3, (2010), pp. 222-238.

[6] B. Ma and Q. Wei, "Measuring the coverage and redundancy of information search services on ecommerce platforms", Electronic Commerce Research and Applications, vol. 11, no. 6, (2012), pp. $560-569$.

[7] Y. Zhang and J. Bian, "Trust fraud: A crucial challenge for China's e-commerce market", Electronic Commerce Research and Applications, vol. 12, no.5, (2013), pp. 299-308.

[8] R. Ramanathan, "An empirical analysis on the influence of risk on relationships between handling ofproduct returns and customer loyalty in E-commerce", International Journal of Production Economics,vol. 130, no. 2, (2011), pp. 255-261

[9] A. Niklas and S. Fredrik, "Electronic commerce, marketing channels and logistics platform-a wholesaler perspective", European Journal of Operational Research, vol. 144, no. 2, (2003), pp. 270-279.

[10] D. Jutla and P. Bodorik, "Developing internet e-commerce benchmarks", Information Systems, vol. 24,no. 6, (1999), pp. 475-493.

[11] S. Nader, "A customer loyalty formation model in electronic commerce", Economic Modeling, vol. 35, (2013), pp.559-564.

[12] J. Kim, "The role of retail quality, e-satisfaction and e-trust in online loyalty development process",Journal of Retailing and Consumer Services, vol. 16, no. 4, (2009), pp. 239-247.

\section{Authors}

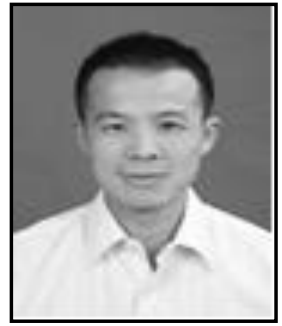

Tang wu-song, he was born on November 1978 in Shihezi,Xinjiang,P,R,China. Current position,grades: the lecturer of College of physical education, Shihezi University,Xinjiang,China. Scientific interest: I research interest fields include Physical Education Teaching and Training. Publications: more than 10 papers published. Experience: I has teaching experience of 13 years, has completed four scientific research projects. 